\title{
Remesas y pobreza: una revisión teórica y empírica*
}

\section{Remittances and Poverty: A Theoretical and Empirical Review}

\author{
Jorge Mora-Rivera** y Francisco Javier Morales Gutiérrez***
}

\begin{abstract}
RESUMEN
Este artículo hace una revisión de estudios que investigan el impacto que tienen las remesas sobre la pobreza en distintas partes del mundo, abordando diferentes concepciones teóricas y presentando evidencias empíricas relevantes que abonan a la discusión de la relación entre ambos fenómenos. Lo anterior con el fin de contribuir a la presentación sintética de las evidencias que existen en esta materia y así ofrecer una guía para aquellos interesados en estudiar ambas temáticas. Los estudios revisados indican que, en general, las remesas contribuyen a disminuir los niveles de pobreza. No obstante, el impacto de las remesas depende en gran medida de las estructuras institucionales existentes en los países de origen y de su efectividad al lidiar con problemas sociales y económicos. Así mismo, resulta fundamental señalar que las remesas por sí mismas no pueden erradicar la pobreza y de ninguna manera deben ser vistas como un mecanismo para ello.
\end{abstract}

Palabras Clave: Remesas, pobreza, desarrollo, migración.

Clasificación JEL: F24, I32, O10, F22.

\begin{abstract}
This paper reviews several studies about the impact of remittances on poverty throughout different countries; addressing different theoretical conceptions and presenting relevant empirical evidence, which serve as material to enrich the discussion that involves both phenomena. This is done in order to present more information to the already existing evidence on this subject, as well as to provide a guide for those who are interested in studying both topics. Previous studies indicate that, overall, remittances contribute favorably to poverty reduction. Nevertheless, the impact of remittances depends on the existing institutional structure within the origin countries and on the effectiveness they have in dealing with social and economic problems. For this reason, it is important to highlight that remittances cannot eliminate poverty by themselves, and thus they should not be considered as a mechanism to poverty eradication.
\end{abstract}

Keywords: Remittances, poverty, development, migration.

JEL Classification: F24, I32, O10, F22.

* Fecha de recepción: 26-11-2015. Fecha de aprobación: 25-10-2017.

** Tecnologico de Monterrey, Campus Ciudad de México. Correo: jjmora@itesm.mx. ORCID: 0000-0003-0838-9551

*** Tecnologico de Monterrey, Campus Monterrey. Correo: francisco.morales.gtz@gmail.com.

ORCID: 0000-0002-4213-0335 


\section{INTRODUCCIÓN}

La pobreza es un tema que preocupa a prácticamente todos los países del mundo, la magnitud de este fenómeno es enorme. De acuerdo con el Informe sobre Desarrollo Humano 2014 del Programa de las Naciones Unidas para el Desarrollo (PNUD):

[...] hay más de 2,200 millones de personas que se encuentran en situación de pobreza multidimensional o cerca de ella. Esto significa que más del 15 por ciento de la población mundial sigue siendo vulnerable a la pobreza multidimensional. Al mismo tiempo, casi el 80 por ciento de la población mundial no cuenta con una protección social integral. Alrededor del 12 por ciento ( 842 millones) de la población padece hambre crónica y casi la mitad de los trabajadores (más de 1,500 millones) tienen empleos informales o precarios (PNUD, 2014).

En el caso de México, según estimaciones del Consejo Nacional de Evaluación de la Política de Desarrollo Social (Coneval) la pobreza aumentó en dos millones de personas entre 2012 y 2014, al pasar de 53.3 millones (45.5 por ciento) a 55.3 millones (46.2 por ciento), lo que indica que el fenómeno está presente en la agenda de desarrollo social del país (Coneval, 2015).

Estudiar y comprender este problema ha sido tarea de varias disciplinas de las ciencias sociales, dentro de las cuales destacan las contribuciones efectuadas por la perspectiva económica, la cual ha aportado distintas herramientas analíticas y teóricas para comprender dicho fenómeno (Sen, 1976; Foster, Greer y Thorbecke, 1984; Alkire y Foster, 2007).

Por otra parte, desde la década de los ochenta, las remesas han adquirido especial importancia en los países en desarrollo, siendo América Latina la región que recibe la mayor cantidad de remesas en el mundo (Acosta et al., 2008). De acuerdo con pronósticos del Banco Mundial, las tasas de crecimiento de las remesas mundiales se ubicarán entre 1.3 por ciento y 4.7 por ciento para el periodo 2015 2018 (World Bank, 2013). Por su parte, México es el país que capta el mayor monto de remesas en América Latina; en 2005 el monto de remesas que llegaron a México representó el 45 por ciento del total en la región y en 2015 registró una entrada de 24,771 millones de dólares por concepto de remesas, lo cual significó un crecimiento de 4.8 por ciento respecto al año anterior (Consejo Nacional de Población, Fundación BBVA Bancomer y BBVA Research, 2015).

Debido a la importancia de las remesas a nivel mundial, se han realizado varios estudios para conocer su dinámica así como el impacto que tienen en varios rubros de la economía y especialmente en indicadores de desarrollo económico 
(Gómez, 2013; Brown, 2006; McKenzie, 2005). Dentro de estos estudios, se ha destacado que los recursos provenientes de los trabajadores migrantes internacionales ayudan a disminuir los niveles de pobreza (Satti et al., 2016; Adams y Page, 2005).

En este contexto, el presente trabajo tiene como objetivo realizar una revisión de los estudios que abordan la relación entre remesas y pobreza. La literatura que trata esta relación indaga las motivaciones para remitir y el impacto que tienen los flujos monetarios en los hogares receptores sobre ciertos indicadores de bienestar, entre ellos la pobreza. En la mayoría de los trabajos revisados, la medición de la pobreza es realizada considerando la perspectiva de líneas de pobreza (Feres y Mancero, 2001), pues hasta el momento existen pocos artículos que relacionen el impacto de las remesas en la pobreza desde una perspectiva multidimensional (Quang, 2015; Sánchez, 2010). Si bien prácticamente todos los estudios consultados señalan que la recepción de remesas ayuda a reducir los niveles de pobreza, no hay un consenso respecto al impacto que tienen las remesas en el desarrollo de las comunidades de origen de los migrantes (Amare y Hohfeld, 2016; Canales, 2016; Durand et al., 1996).

Los estudios empíricos que indagan la relación de remesas y pobreza reconocen los problemas metodológicos asociados con ambos fenómenos, los cuales pueden generar resultados que distorsionan la relación a explorar (Adams, 2011). Dichos estudios utilizan cada vez más información proveniente de encuestas a hogares en países en desarrollo (Adams y Cuecuecha, 2013), cuya información, en algunos casos, ha permitido estudios comparables entre países en desarrollo y ha posibilitado conocer en qué medida las remesas han impactado en los niveles de pobreza entre estos países (Hossain, 2013; Hagen-Zanker y Leon, 2016). Así mismo y con el propósito de corregir los problemas asociados al estudio de la migración y las remesas, las investigaciones empíricas más recientes incorporan técnicas que les permiten obtener mayor precisión y robustez en sus resultados (Gibson, McKenzie y Zia, 2014; Yang, 2008).

Los trabajos incluidos provienen de distintos países en desarrollo de Asia, África y América Latina, cuya característica común consiste en tener una destacada vocación migratoria, así como registrar niveles de pobreza considerables. La mayor parte de los estudios se enfocan en localidades rurales, ya que éstas presentan las peores condiciones de bienestar y pobreza, al mismo tiempo que están sujetas a mayor vulnerabilidad, ya sea por choques climáticos desfavorables o por falta de infraestructura productiva y escaso desarrollo de los mercados locales (Adams, 1991 y 2004; Hatemi-J y Salah; 2014; Joseph y Wodon, 2014). La relevancia de estas investigaciones radica en que los resultados a los que arriban les permiten sugerir medidas de política que permitan impulsar el desarrollo en las 
comunidades de origen de los migrantes (Amuedo-Dorantes y Pozo, 2004; Brown, 2006).

Además de la introducción, este trabajo se organiza en dos grandes secciones. En la primera se hace una revisión del surgimiento y evolución teórica de los dos temas del artículo: remesas y pobreza. En esta sección se describen las distintas perspectivas en el estudio de las remesas, considerando desde la decisión que toma el migrante al incorporarse al flujo migratorio, las distintas explicaciones teóricas sobre las motivaciones para remitir y los impactos que las remesas tienen en el corto y largo plazo. Adicionalmente, se incluye una descripción sobre la conceptualización y medición de la pobreza y la forma en cómo las remesas constituyen una opción para los hogares pobres. En la segunda sección se mencionan los problemas metodológicos a los que se enfrentan los estudios empíricos de remesas, así como una revisión de la literatura de los distintos trabajos que se han elaborado para explorar la relación entre remesas y pobreza, tanto a nivel de localidad o país, entre distintos países y una subsección especial para el caso mexicano.

\section{NATURALEZA Y EVOLUCión DE LOS CONCEPTOS}

En este apartado se hace un recuento de los estudios teóricos de las remesas y de la conceptualización y medición de la pobreza, ambos temas han sido analizados con diversas finalidades y es de nuestro interés indagar sobre la naturaleza de estos conceptos, así como de la relación que entre ellos guardan.

\section{I.1. Remesas y los motivos para su envio}

De acuerdo con Yang (2011) las remesas son ingresos de los hogares provenientes del exterior, resultado principalmente del envío de recursos monetarios por parte de los trabajadores migrantes internacionales. Estos recursos son enviados como dinero en efectivo o en especie y pueden fluir en varios canales formales e informales (Orozco, 2004).

Las remesas son contabilizadas en la balanza de pagos de los países receptores y son medidas como la suma de dos categorías de transacciones: remesas de los trabajadores y remuneración de los asalariados. Las remesas de los trabajadores son dinero en efectivo y recursos que no están en efectivo, mandados por los migrantes residentes en el exterior. Las transacciones en esta categoría son explícitamente definidas como transacciones unilaterales, las cuales no involucran un intercambio económico, es decir, la transacción no debe ser un pago por un bien o servicio (FMI, 2009). 
Rapoport y Docquier (2006) identifican dos perspectivas en los estudios de las remesas. La primera relacionada con las motivaciones para su envío, aquí se contemplan el papel de las interacciones sociales y el rol de la información, los cuales se relacionan con los trabajadores migrantes; lo que implica que son decisiones relacionadas con temas microeconómicos. Las motivaciones que existen para enviar remesas son: altruismo, intercambio, componente estratégico, seguros y arreglos familiares. La segunda perspectiva está relacionada con los impactos que las remesas tienen en los niveles de consumo, inversión, oferta de trabajo, pobreza y desarrollo de las comunidades receptoras; esto es, variables económicas que se identifican con aspectos macroeconómicos.

La motivación altruista plantea una relación directa entre el ingreso del migrante y los montos de la transferencia cuando la suma de los ingresos de la familia receptora es baja; en contraste, si el ingreso de las familias receptoras se incrementa, las transferencias se reducen (Lucas y Stark, 1985; Stark, 1995). Los estudios que abordan la motivación altruista han investigado sobre la estabilidad en el envío de remesas (Azizi, 2017) y el comportamiento de éstas cuando los países de origen de los migrantes internacionales experimentan un choque externo, ya sea por fenómenos naturales (Yang, 2008) o por crisis económicas (Tchouassi, 2010).

Otra de las motivaciones para remitir se relaciona con el hecho de que las remesas pueden comprar varios tipos de servicios, como el cuidado de activos y de familiares que se quedan en el lugar de origen. También se considera que, debido a las imperfecciones del mercado, los costos de transacción deben ser ahorrados mediante arreglos fuera del mercado, por ejemplo, los migrantes deben reembolsar los préstamos otorgados para la realización del viaje al país donde trabajarán o los derivados en la inversión de capital humano (costo de la educación). Los acuerdos a los que llegan dependerán de las negociaciones entre las partes y los pagos se asemejarán a los costos de los servicios en el mercado (Cox, 1987). Los estudios que contrastan empíricamente esta motivación señalan que los hogares con un familiar migrante tienen mayor probabilidad de mantener la recepción de remesas, lo que se convierte en un elemento importante en el ingreso del hogar (Cox, Eser y Jimenez, 1998; Chakraborty, Mirkasimov y Steiner, 2015).

El componente estratégico fue desarrollado inicialmente por Stark (1995) y parte de la consideración de que las remesas son tanto causa como consecuencia de la migración, por tanto ambas decisiones deben estudiarse de forma interdependiente. Las remesas pueden ser parte de una interacción estratégica orientada a la selección positiva de los migrantes. Esto significa que los empleadores en el país de destino desconocen las habilidades de los migrantes y les paga un salario promedio acorde a la productividad de la minoría étnica a la cual pertenezcan, por tanto, se crea un incentivo para que trabajadores con pocas habilidades emigren 
dado el salario que podrían percibir. De acuerdo con este motivo, la migración será selectiva desde el comienzo, la selectividad y las remesas están relacionadas en forma positiva. Docquier y Rapoport (1998) contrastan la hipótesis de Stark y señalan que debido a que la productividad individual no es observable en el país receptor, a los migrantes se les paga la productividad promedio del grupo en el que son identificados. Por esta razón, los trabajadores calificados pueden tener un incentivo para enviar remesas con la finalidad de mantener a los trabajadores no calificados en su país de origen porque la migración de estos trabajadores puede significar una reducción de los salarios para los trabajadores calificados.

Para explicar el componente de seguros y riesgo moral, se hace la consideración de la volatilidad del ingreso en las familias receptoras, la motivación para enviar recursos monetarios se sustenta en el deseo del migrante en proporcionar un respaldo al hogar receptor cuando las condiciones económicas sean adversas (Rapoport y Docquier, 2006). En esta perspectiva, el envío de remesas es constante durante un periodo determinado, especialmente cuando los ingresos de las familias receptoras caen. Amuedo-Dorantes y Pozo (2006) hacen un estudio de los migrantes mexicanos y encuentran que de acuerdo con las adversidades que enfrenten en su estadía en Estados Unidos, los migrantes pueden destinar una parte de sus ingresos para constituir un seguro de desempleo o una probable reducción de su salario. Arezki y Brückner (2012) calculan los efectos de choques en el ingreso debido a la sequía en países de África Subsahariana, sus resultados revelan que no hay un impacto directo de la sequía en el envío de remesas.

Entre los arreglos familiares previos a la migración es posible señalar que las remesas también pueden ser consideradas como reembolso de un préstamo invertido en la educación o en el traslado al país de destino. A los aspectos relacionados con estas consideraciones se le conoce como el componente de inversión y puede ser visto como un intercambio de servicios en un contexto de mercado de crédito imperfecto (Rapoport y Docquier, 2006). Los trabajos que indagan esta motivación llegan a resultados que muestran una relación entre los préstamos otorgados y el envío de remesas (Ilahi y Jafarey, 1999; Hagen-Zanker y Siegel, 2007), además muestran la existencia de una relación inversa entre el nivel de educación y la probabilidad del envío de remesas (Durand et al., 1996; Osaki, 2003).

El respeto a los acuerdos familiares es otro aspecto a considerar, puede existir el estímulo a no respetarlos si quien está enviando remesas no percibe los beneficios del arreglo. Ante esta posibilidad, una forma de hacer respetar el acuerdo es considerar a las remesas como una inversión para recibir una parte de la herencia familiar, ya sea en forma de tierras o de activos que la familia receptora posee (Hodinott, 1994; Osili, 2004). Dentro de esta motivación se señala que existe una relación positiva entre la aversión al riesgo de los migrantes y la probabilidad de enviar remesas (Batista y Umblijs, 2016). 


\section{I.2. Impactos de las remesas en indicadores económicos de los países de origen}

En este apartado se presentan estudios relacionados con el impacto de las remesas en las economías de los países de origen de los migrantes internacionales. Se consideran los efectos de corto plazo que se relacionan con el consumo, los precios relativos y en los indicadores del nivel de bienestar. También se exploran otros campos en donde las remesas pueden incidir, por ejemplo, para impulsar la inversión o atenuar la desigualdad en los países receptores.

Una de las consideraciones para analizar el impacto de las remesas en las economías de los países de origen es el incremento en el número de migrantes desde la década de los ochenta del siglo xx y con ello el aumento en el flujo de remesas hacia países en desarrollo (De Haas, 2010). Las remesas se convirtieron en una importante fuente de transferencias privadas y han generado interrogantes sobre su posible contribución al crecimiento económico en los países de origen mediante su posible influencia en la inversión y en el tipo de cambio (Ratha y Mohapatra, 2007; Guiliano y Ruiz-Arranz, 2009). Así mismo, se ha argumentado que las remesas pueden promover un consumo poco útil (incluso no saludable) en las economías de los países de origen, además de su impacto negativo en la producción local por la reducción en la mano de obra (Chami, Fullenkamp y Jahjah, 2005).

Otro de los aspectos estudiados sobre los efectos de las remesas en el corto plazo está relacionado con el hecho de que la creciente magnitud de las remesas provoca un auge en los ingresos por divisas en el país que es similar al fenómeno de auge de recursos que dio lugar a la "enfermedad holandesa". El aumento de las remesas da lugar a la apreciación del tipo de cambio real, causando que el sector exportador de la economía se colapse y por tanto el país receptor pierda competitividad externa (Chami, Cosimano, y Gapen, 2006; Guha, 2013). Estos trabajos han logrado demostrar que las remesas provocan una apreciación del tipo de cambio real, utilizando como marco metodológico a los modelos de equilibrio general; sin embargo, pocos de ellos han logrado establecer cuál es el canal mediante el cual las remesas provocan una pérdida de competitividad en la economía receptora (Guha, 2013).

Con respecto a los efectos de largo plazo, se han explorado los impactos que las remesas tienen sobre el nivel de consumo e inversión. Estos estudios se enfocan en averiguar si el uso de las remesas ayuda a mejorar la productividad y con ello pueden impulsar el crecimiento de la producción en los países receptores (Brown, 2006). 
Cox y Ureta (2003) realizan un estudio del impacto de las remesas en las decisiones escolares de los hogares con miembros migrantes en El Salvador. En este trabajo se encuentra que las remesas tienen un pequeño, aunque significativo, impacto en el riesgo de abandonar la escuela en las áreas rurales y urbanas. Los resultados a los que llegan sugieren que subsidiar la asistencia escolar particularmente en las áreas más pobres, puede tener un mayor impacto en la asistencia escolar y la retención, aun si los padres tienen bajos niveles educativos.

Levitt y Lamba-Nieves (2011), en su estudio de República Dominicana, muestran que existe un efecto negativo de las remesas en la educación. Los hijos de los migrantes no tienen incentivo para ir a la escuela o encontrar un trabajo, porque están esperando salir del país o en su defecto, el dinero enviado por sus familiares en el extranjero los incentiva a permanecer en el ocio.

Entre los estudios que indagan el impacto de las remesas en el desarrollo de un país receptor se encuentra el trabajo de Gómez (2013) quien señala que las remesas tienen los siguientes efectos:

[...] a escala nacional, las remesas son una importante fuente de activos en la balanza de pagos, $d$ ) las remesas contribuyen a la economía doméstica de los hogares receptores, $e$ ) las remesas, como variable independiente no son ni pueden ser un factor de desarrollo, $f$ ) si bien hay efectos multiplicadores de las remesas, el carácter acumulativo de los movimientos migratorios conduce a un drenaje de población en ciertas regiones. (Gómez, 2013: 171).

Brown (2006) plantea que los efectos de las remesas en el bienestar dependen de la condición de los hogares receptores y en general serán aquellos hogares que se encuentren en niveles muy bajos de bienestar quienes serán los más beneficiados con en el envío de remesas. Según este autor, el flujo de remesas puede ayudar a impulsar el desarrollo de un país, sólo se requiere que el país de origen de los migrantes cuente con instituciones que sean capaces de aprovechar esta fuente de ingreso externo.

\section{I.3. Pobreza y sus enfoques para su medición}

En este trabajo nos interesa abordar el tema de la medición de la pobreza y su vinculación con los estudios de remesas. Por esta razón, este apartado presenta en primer lugar algunas de las concepciones que existen sobre el fenómeno de la pobreza y que se relacionan con la identificación y agregación de personas $\mathrm{u}$ hogares pobres. Posteriormente se describen la familia de índices que se han 
construido para la medición de la pobreza. Dentro de las medidas de pobreza destaca el avance de la perspectiva multidimensional que aporta elementos de análisis para una mejor comprensión de este fenómeno al integrar aspectos no monetarios en las mediciones realizadas.

\section{I.3.1. Conceptualización de la pobreza}

Existen muchas definiciones acerca de la pobreza, para algunos autores la pobreza es la carencia de recursos necesarios para la vida humana (Sánchez Almanza, 2010); sin embargo, la naturaleza del concepto puede ser diversa. Para Rowntree (1901: 87) la pobreza "[...] es monto de dinero socialmente aceptable para lograr las necesidades mínimas para el simple mantenimiento de la eficiencia física". El Programa de Naciones Unidas para el Desarrollo (PNUD) señala que la pobreza "[...] es la imposibilidad de las personas para vivir una vida tolerable" (PNUD, 1997: 18). También podemos señalar que la concepción de la pobreza puede estar asociada a diversos factores, entre ellos "[...] necesidad, estándar de vida, insuficiencia de recursos, carencia de seguridad básica, falta de titularidades, privación múltiple, exclusión, desigualdad, clase, dependencia y padecimiento inaceptable" (Spicker, 2007). En 1968, el Social Science Research Council proporcionó el siguiente concepto de pobreza "[...] los individuos son pobres porque no tienen las oportunidades, comodidades y dignidad que se consideran normales en la comunidad a la que pertenecen. Por tanto, son las normas medias continuamente cambiantes de esa comunidad las que constituyen los puntos de partida para el cálculo de la pobreza; los pobres son aquellos que se encuentran lo suficientemente por debajo de esos niveles medios" (Atkinson, 1991: 56).

Estas definiciones implican otras problemáticas y tienen que ver con la forma en que las privaciones o carencias deben ser concebidas o medidas. Las consideraciones comenzaron a partir del concepto de pobreza planteado por Rowntree que se relaciona con aspectos monetarios, el cálculo de una canasta que incluyera aspectos como alimentación, ropa y vivienda definió lo que se ha denominado línea de pobreza (Ponce, 2013).

Ante la concepción puramente económica de la pobreza, surgieron respuestas que abogaron por incluir aspectos sociales dentro de su medición. De acuerdo con Townsend (1993), las necesidades del ser humano están determinadas socialmente, por tanto las necesidades de sobrevivencia dependerán de la forma en cómo se conciben y se satisfacen en el contexto social. Según estas consideraciones, la inclusión de la dimensión social dio lugar al método de necesidades básicas insatisfechas como una alternativa para medir los niveles de pobreza. Un enfoque adicional que se ha planteado para la medición de la pobreza es el de la Medición Integrada de la 
Pobreza, el cual combina valores de los métodos de la línea de pobreza y de necesidades básicas insatisfechas (Sánchez Almanza, 2010 y Ponce, 2013).

Sin duda, uno de los trabajos más relevantes relacionados con el estudio de la pobreza es el de Sen (1976), en el cual se establece que la pobreza puede estudiarse mediante tres componentes. El de incidencia, a través del cual se identifica a un individuo $u$ hogar pobre, el segundo componente es el de intensidad que determina el grado o magnitud de la pobreza, el último componente es el de la desigualdad entre los pobres, el cual actúa como factor agravante del fenómeno. Este enfoque enunciado por Sen se conoce como el enfoque del desarrollo humano y ha dado lugar a considerar a la pobreza como un fenómeno multidimensional.

\section{I.3.2. Agregación e identificación de las personas u hogares pobres}

El proceso de medición de la pobreza obliga por una parte a identificar aquellas unidades de análisis que se consideran pobres y por otra a la agregación del bienestar de tales unidades de análisis en una medida de pobreza. Así, la cuantificación de la pobreza abarca aspectos conceptuales y metodológicos muy variados que el investigador debe abordar al elegir un método de cuantificación (Domínguez y Martín, 2006).

Una medida de pobreza consiste en dos etapas: identificación y agregación. En la etapa de identificación se busca ubicar a las personas u hogares pobres mediante indicadores de bienestar y de esta manera determinar quiénes presentan está condición y quiénes no. Dentro de esta etapa se distinguen los principales métodos de medición, apuntando que existe una serie de decisiones relacionadas que son propias de la medida de pobreza utilizada, estas son: la unidad de análisis, típicamente personas, familias u hogares; las variables a utilizar en la identificación de la pobreza; la fuente de información para la construcción del índice respectivo; y el umbral definido como mínimo, bajo el cual se considera que una persona se encuentra en situación de pobreza (Denis, Gallegos y Sanhueza, 2010).

Una vez que se define un método de identificación, en la etapa de agregación se establecen los criterios por los cuales una familia o una persona serán consideradas pobre o no pobre y se procede a sintetizar la información en una cifra única. Con esta finalidad, se usan distintos métodos de agregación que permitan indicar la extensión y el estado actual de la pobreza, los cuales son aspectos fundamentales para la comparación de los niveles de pobreza en distintas situaciones (Denis, Gallegos y Sanhueza, 2010). En la etapa de agregación Sen (1976) propone un enfoque axiomático que reúne una serie de condiciones necesarias para una medida de pobreza. Dichos axiomas son: focal, monotonicidad, transferencia y monotonicidad en subgrupos (Sen, 1983). Bourguignon y Chakravarty (2003) seña- 
lan que los axiomas más importantes para la identificación de las personas u hogares pobres son: focal fuerte, focal débil, simetría, continuidad, principio de la población, monotonía, descomposición en subgrupos, escala de invarianza y transferencia.

\section{I.3.3. Índices de pobreza}

Según el enfoque axiomático de Sen, una familia de índices de pobreza que es utilizada frecuentemente es la propuesta por Foster, Greer y Thorbecke (1984) que se construyen de acuerdo con la siguiente ecuación:

$$
F G T=\frac{1}{N} \sum_{i=1}^{q}\left(\frac{z-y_{i}}{z}\right)^{\alpha}
$$

Donde $N$ es la población total, $q$ el total de pobres, $z$ la línea de pobreza e $y_{\mathrm{i}}$ es el ingreso del $i$-ésimo individuo pobre. Por tanto, según el valor al parámetro $\alpha$ se obtienen distintas medidas de agregación. Las medidas más utilizadas son:

El índice de incidencia de la pobreza o índice de recuento que mide la proporción de personas que se encuentra bajo la línea de pobreza. Este índice se obtiene cuando $\alpha=0$ en la fórmula FGT básica. El índice de recuento satisface el axioma focal y se puede descomponer aditivamente, sin embargo no ofrece información sobre qué tan pobres son los pobres y no considera los aspectos distributivos de la población pobre (Feres y Mancero, 2001).

La brecha de pobreza que se construye a partir de asignar el valor $\alpha=1$ en la fórmula FGT, mide el déficit del ingreso de la gente pobre con respecto al valor de la línea de pobreza. El índice de la brecha de pobreza satisface los axiomas focales y de monotonicidad; es decir, si el ingreso de una persona pobre disminuye, el promedio de ingresos también se reducirá y el índice de brecha de pobreza aumenta. Sin embargo, esta medida no cumple con el axioma de transferencia porque un traspaso de ingresos de una persona pobre a una persona menos pobre no se reflejará en este índice (Alkire y Foster, 2007).

El índice de severidad de la pobreza también conocido como FGT2 que resulta de asignar el valor $\alpha=2$ en la fórmula FGT. Este índice mide la distancia media de ingreso de los pobres al cuadrado, con respecto a la línea de pobreza. Satisface el axioma de transferencia así como los axiomas focal y de monotonicidad (Foster, Greer y Thorbecke, 1984).

Este grupo de medidas tienen como característica que son aditivamente separables, esto es que la medida agregada de pobreza se puede escribir como la suma 
de medidas de pobreza individuales, lo que permite a su vez que la medida agregada pueda desagregarse como un promedio ponderado de las medidas de pobreza de distintos subgrupos excluyentes de la población, donde los ponderadores corresponden al peso de cada grupo en la población (Alkire y Santos, 2013).

\section{I.3.4. Pobreza multidimensional}

Como resultado de la discusión que se ha desarrollado en torno al fenómeno de la pobreza tanto en su parte conceptual como metodológica, la perspectiva multidimensional se ha incorporado a dicha discusión (Alkire y Foster, 2007). Se hace la consideración que la pobreza es un problema social multidimensional en sus causas y efectos. No existe consenso en torno a cómo decidir qué dimensiones son las propiamente referentes de la pobreza y cómo construir un modelo de análisis que permita abordar dicha multidimensionalidad (Denis, Gallegos y Sanhueza, 2010).

La relevancia que ha adquirido el análisis multidimensional se debe al creciente cuestionamiento del análisis unidimensional de este fenómeno basado en el ingreso, surgiendo de ello la necesidad de considerar un enfoque adicional que contemple nuevas dimensiones relacionadas con la pobreza, de manera que la mediciones realizadas proporcionen una mejor evaluación de este problema social (Bourguignon y Chakravarty, 2003).

Desde la perspectiva multidimensional se considera una sociedad de $n$ individuos de los cuales se observan características en $m$ dimensiones. Se define una matriz $\boldsymbol{X}$ como aquella tal que su elemento $x_{\mathrm{ij}}$ es la cantidad que la persona $i$ posee del bien o atributo correspondiente a la dimensión $j$ y el vector correspondiente se denomina $z$. Una medida de pobreza queda caracterizada por dos funciones: una función de identificación $p\left(x_{\mathrm{i}}, z\right)$ que toma el valor 1 para los individuos considerados pobres multidimensionalmente y 0 en otro caso, y una función de agregación que se denota como $P(X, z)$ y genera una medida agregada de la pobreza en una sociedad determinada (Alkire y Santos, 2013).

Las medidas multidimensionales de pobreza se pueden clasificar en dos grupos de acuerdo con la existencia de sus propiedades matemáticas. Por una parte se encuentran las formulaciones no axiomáticas que son: Índice de Necesidades Básicas Insatisfechas (NBI); Índice de Pobreza Humana (IPH); Análisis de componentes principales y otros métodos factoriales e Índice de privaciones (Alkire y Santos, 2013).

El segundo grupo de medidas multidimensionales son las relacionadas con formulaciones desde el enfoque axiomático, destacando los modelos de Bourguignon y Chakravarty (2003) y Alkire y Foster (2007). 


\subsection{Factores que contribuyen en el combate a la pobreza}

Como ya se mencionó previamente, erradicar la pobreza constituye uno de los principales objetivos de la humanidad (PNUD, 2016). Atender dicha problemática representa un tema bastante complejo que abarca cuestiones multidisciplinarias en las agendas nacionales e internacionales (Battiston et al., 2013).

A pesar de que los esfuerzos para combatir la pobreza han sido amplios, los resultados no han sido suficientes y ahora es posible reconocer que la solución no es única y debe estar compuesta por un conjunto de medidas que agreguen y complementen las acciones de cada caso en particular (PNUD, 2014). Algunas de las medidas que contribuyen al combate a la pobreza son: 1) los programas gubernamentales diseñados para dicho efecto (Araujo, Bosch y Schady, 2016; DFID, 2011); 2) los recursos provenientes del exterior conocidos como cooperación internacional para el desarrollo, que básicamente lo constituyen los recursos financieros internacionales encabezados por distintos organismos transnacionales como la Organización para la Cooperación y el Desarrollo Económicos, el Banco Mundial, el Banco Interamericano de Desarrollo y el PNUD (Monni y Pallottino, 2016; PNUD, 2016; OECD, 2013), y 3) el envío de transferencias privadas (remesas) que los migrantes internacionales realizan a su país de origen (Amare y Hohfeld, 2016; Acosta et al., 2008; Adams y Page, 2005).

Respecto a los programas de gobierno, es posible señalar que se ha registrado un crecimiento en el número y los montos asignados a los mismos en cada país. El diseño, alcance y objetivos de los programas de transferencias focalizados en el combate a la pobreza deberían reflejar, en gran medida, el escenario y contexto local sobre lo que funciona mejor para la reducción de la pobreza en cada contexto, considerando las capacidades institucionales en cada lugar en que dichos programas se implementan (Araujo, Bosch y Schady, 2016; Levy, 2006). Algunos ejemplos de países que han implementado este tipo de programas son México, Colombia, Chile, India, China, entre otros (DFID, 2011).

Por su parte, la cooperación internacional representa un esfuerzo complementario a los nacionales con la finalidad de contribuir a la reducción de la pobreza (ONU, 2015; OECD, 2013). Así mismo, este tipo de ayuda ha sido utilizada como instrumento de política exterior, que surge como esfuerzo complementario a los propios de cada Estado (Sierra, 2015). El combate a la pobreza constituye así un eje prioritario de la agenda internacional para el desarrollo, siendo tanto en los Objetivos de Desarrollo del Milenio (ODM) como en los Objetivos de Desarrollo Sostenible (ODS) el objetivo número uno (PNUD, 2016).

Uno de los flujos monetarios más importantes en todo el mundo lo constituye el envío de remesas que los migrantes internacionales hacen a sus países y/o luga- 
res de origen (World Bank, 2013; Adams y Page, 2005). En este sentido y según resultados de diversas investigaciones, las remesas constituyen una fuente de ingresos con un potencial importante en el combate a la pobreza (Hossain, 2013; Hagen-Zanker y Leon, 2016; Acosta et al., 2008). Este rápido aumento en el flujo de dinero enviado a los países en desarrollo genera no sólo efectos directos en los lugares receptores, sino también tiene el potencial de generar impactos multiplicadores que se pueden extender más allá de los hogares que las reciben (Yang, 2011). Por tanto, las remesas constituyen uno de los recursos con mayor efecto potencial en temas de desarrollo y bienestar económico para las regiones expulsoras (De Haas, 2010).

\section{I.5. La Nueva Economía de la Migración Laboral y la interacción entre remesas y pobreza}

En la literatura que aborda el tema de las remesas se han planteado, entre otras, las siguientes interrogantes ¿por qué los migrantes envían remesas? ¿qué impactos tiene el envío de las remesas en las comunidades de origen tanto en los hogares receptores como en los no receptores? ¿qué destino se les da a las remesas en los hogares receptores? ¿las remesas representan una oportunidad para que los hogares receptores salgan de su condición de pobreza? (Adams y Cuecuecha, 2013; Amuedo-Dorantes y Pozo, 2011; Adams 2011). Para dar respuesta a estas preguntas, una vertiente teórica de la migración que proporciona elementos de análisis para responder al cuestionamiento sobre el impacto de las remesas en los niveles de pobreza en las localidades de origen es La Nueva Economía de la Migración Laboral (Stark y Bloom, 1985). Esta perspectiva postula a los hogares como el elemento central en la decisión de emigrar, quienes construyen una estrategia de migración para maximizar sus ingresos y reducir sus riesgos económicos.

Según la teoría de la Nueva Economía de la Migración Laboral, las remesas constituyen un ingreso adicional para los hogares receptores que en su mayoría se ubican en localidades rurales (Taylor, Rozelle y de Brauw, 2003). En estas localidades, las actividades principales que generan ingresos son la agricultura y la ganadería, las cuales se ven sujetas a las condiciones de clima y de los mercados locales. Así mismo, gran parte de las localidades rurales registran los niveles de pobreza más elevados (Coneval, 2015) y esta situación genera que se pongan en acción distintas medidas orientadas en reducir está condición.

Las localidades rurales tienen un reducido acceso a los mercados de crédito, ya sea por ausencia de éstos o por un mal funcionamiento de los mismos. En ausencia de mercados de crédito los hogares pueden utilizar las remesas para comprar 
insumos de producción para mejorar la producción en las actividades agrícolas y no agrícolas (Sindi y Kirimi, 2006). Por tanto, las remesas podrían representar una fuente de capital escaso para los hogares y proveer un seguro contra los riesgos emanados de nuevas actividades y tecnologías de producción.

De acuerdo con estas consideraciones, se ha planteado que las remesas pueden tener impactos directos en los niveles de pobreza de las localidades de origen porque permiten sustentar las necesidades básicas de los hogares (alimentos y vestido) y también permiten financiar proyectos de inversión que permiten generar empleos en las localidades rurales, beneficiando a los hogares receptores y a los hogares no receptores (Adams y Cuecuecha, 2013). Por su parte, los efectos indirectos de las remesas se observan por ejemplo en el hecho de que permiten incrementar la asistencia escolar y con ello contribuyen a la formación de capital humano (Cox y Ureta, 2003), del mismo modo incentivan el acceso a los servicios de salud de los miembros de hogares receptores (McKenzie, 2005).

\section{REVISIÓN Y ANÁLISIS DE LOS ESTUDIOS EMPÍRICOS SOBRE REMESAS Y POBREZA}

\section{II.1. Modelos econométricos y los problemas que deben superar}

Existen al menos cuatro problemas metodológicos al que se enfrentan los trabajos de remesas internacionales desde una perspectiva económica: simultaneidad, causalidad inversa, sesgo de selección y sesgo por variables omitidas (Adams, 2011). El primer problema se origina porque muchas de las decisiones sobre migración internacional, remesas, oferta de trabajo y educación son realizadas de forma simultánea. Las variables que causan la migración internacional y el envío de remesas también explican los patrones de consumo, salud y educación de los hogares. Este problema es detectado en los trabajos de Manic (2016); Docquier, Rapoport y Salomone (2012) y Gibson, McKenzie y Stillman (2013).

La causalidad inversa implica que, si bien las remesas internacionales pueden ayudar a reducir la pobreza en los países en desarrollo, el nivel de pobreza también puede influir en el monto de remesas recibidas (Adams, 2011). Por tanto, cualquier intento para analizar el impacto de las remesas en la pobreza que no considere la causalidad inversa entre estas dos variables puede conducir a conclusiones erróneas. Los estudios que han considerado esta problemática son los de Ambrosius y Cuecuecha (2016); Amuedo-Dorantes y Pozo (2011) y Abdih et al., (2012).

El sesgo de selección surge cuando las muestras no son aleatorias, es decir no representan adecuadamente la población que desea estudiarse. Adams (2011) señala que las personas que tienden a migrar y a recibir remesas confunden el trabajo 
con la migración y las remesas. Si por ejemplo, los hogares con mayores niveles educativos o de ingreso tienen mayor probabilidad de recibir remesas, entonces es imposible identificar los efectos de las remesas mediante la comparación de las características de los hogares migrantes y los no migrantes. Si hay una selección positiva, los hogares con mayor nivel educativo o de ingreso tendrán mayores probabilidades de recibir remesas. Entre los trabajos que tienen presente este problema se ubican los artículos de Wagle (2012) y Stephenson y Wilsker (2016).

Cuando los hogares colocan migrantes o reciben remesas sobre la base de características no observables (por ejemplo, aversión al riesgo del jefe de familia), entonces surge el problema del sesgo por variable omitida (Adams, 2011). Es posible que los hogares con jefes de familia con mayor aversión al riesgo tendrán menor probabilidad de enviar migrantes y recibir remesas, pero es muy difícil conseguir datos confiables de esta problemática. Como resultado, la omisión o la falta de variables en el análisis puede llevar a conclusiones sesgadas. Esta problemática se ha estudiado en forma limitada y sólo se pudo ubicar en los trabajos de Osili (2007) y Catrinescu et al., (2009).

Entre las posibles soluciones a estos problemas se pueden mencionar: el uso de experimentos aleatorios (creación de grupos de control) que la han realizado Doi, McKenzie y Zia (2014) y Gibson, McKenzie y Zia (2014); los experimentos naturales (usar un choque externo de la naturaleza) que fueron implementados por Yang y Martinez (2006) y Yang (2008); uso de datos panel que ha ganado bastante aceptación (Acosta et al., 2008; Majeed, 2015); y construir una situación contrafactual, que implica construir artificialmente el estado de un hogar migrante como si no hubiera tenido migrantes, la aplicación de esta solución la han realizado McKenzie, Gibson y Stillman (2007) y Hobbs y Jameson (2012).

\section{II.2. Remesas y sus efectos en los niveles de pobreza en los países de origen}

Entre los estudios que se han realizado a nivel país se encuentra el de Adams y Cuecuecha (2013) cuyo objetivo es examinar cómo son gastadas las remesas internas e internacionales por los hogares de Ghana y su efecto en la pobreza, utilizando una encuesta sobre estándares de vida. En este trabajo se enfrentan a los problemas de selección y de potencial simultaneidad. Para solucionar dichos problemas los autores hacen uso de variables instrumentales y de un modelo probit multinomial. Los autores resaltan tres hallazgos. Primero, cuando se compara lo que habrían gastado sin la recepción de remesas, los hogares receptores gastan menos en alimentos. Segundo, los hogares receptores gastan más en tres bienes de inversión: educación, vivienda y salud. Tercero, la recepción de remesas reduce en 
gran medida la probabilidad de encontrarse en pobreza. Estos hallazgos apoyan la visión creciente que las remesas pueden reducir la pobreza e incrementar la inversión en los países en desarrollo.

Hatemi-J y Salah (2014) investigan la relación causal entre remesas y reducción de la pobreza en Bangladesh en el periodo de 1976 a 2010. El estudio realiza un análisis de cointegración entre las variables remesas y pobreza. Los resultados de la estimación revelan que hay una relación de equilibrio a largo plazo entre las remesas y la reducción de la pobreza. La causalidad bidireccional entre remesas y la reducción de la pobreza también se obtuvo mediante simulaciones bootstrap con ajustes de apalancamiento. Por tanto, las remesas y la reducción de la pobreza están causalmente reforzadas mutuamente, lo que indica que uno de los mecanismos más importantes para la reducción de la pobreza en Bangladesh son las remesas de trabajadores migrantes.

Joseph y Wodon (2014) desean evaluar si el impacto de las remesas en la pobreza y en los indicadores de desarrollo humano depende de las áreas en las que se asientan los hogares. La hipótesis que plantean es que las remesas pueden tener un gran impacto en las áreas afectadas por un clima desfavorable porque en estas áreas los hogares tienden a ser más vulnerables. Al combinar los datos de una encuesta a hogares y el clima en Yemen, se prueba si las remesas domésticas e internacionales reducen la pobreza y mejoran la educación y los indicadores de desnutrición en áreas con altas temperaturas y pocas lluvias. El método de estimación que utilizan les permite indagar el impacto de las remesas en una gama de resultados, entre ellos se encuentran el estatus de pobreza del hogar (basado en el consumo por adulto equivalente) así como en la inscripción escolar de niños menores a 15 años, inmunización para niños menores a cinco años y desnutrición. Sus resultados indican que las remesas son proclives a tener impactos positivos en las medidas de pobreza, asistencia escolar y en medidas de desnutrición. El impacto de las remesas internacionales tiende a ser mayor que las remesas domésticas, probablemente porque entre los beneficiarios, el monto de remesas recibidas es mayor. El impacto de las remesas (especialmente las internacionales) en las medidas de pobreza y desnutrición es mayor en áreas afectadas por altas temperaturas con bajos niveles de lluvia, es decir en regiones que son más vulnerables.

El trabajo de Satti et al., (2016) busca probar empíricamente el impacto del crecimiento económico, las remesas, la población rural y tasa de alfabetización en la pobreza en Pakistán. Para realizar su estudio, aplican el método de pruebas de límites ARDL y el modelo de corrección de errores vectoriales (VECM por sus siglas en inglés) en el periodo 1978 a 2011. Los resultados a los que arriban muestran que el crecimiento económico reduce la pobreza, las remesas contribuyen también a la reducción de la pobreza. También señalan que la población rural se reduce con el 
crecimiento económico y las remesas. Los autores apuntan que hay una causalidad bidireccional entre el crecimiento económico y la pobreza. Además existe un efecto de retroalimentación entre las remesas de trabajadores migrantes y la pobreza.

El estudio de Amare y Hohfeld (2016) plantea que la importancia de las remesas en los hogares rurales es considerable, sin embargo los resultados sobre sus efectos en el bienestar de los hogares es ambiguo. El impacto general de la migración y las remesas en el origen de la dinámica del bienestar permanece como una pregunta empírica abierta. El estudio realizado por estos autores vincula dos áreas en la economía de la pobreza: el método basado en la dinámica del patrimonio y la teoría de la Nueva Economía de la Migración Laboral. El artículo reconoce que las diferencias de los resultados de bienestar entre los receptores de remesas y los no receptores podrían ser debido a una heterogeneidad no observada (por ejemplo, habilidades, capacidad, motivación, cultura, distancia, lenguaje, calidad de la educación, entre otras). Los resultados a los que llegan indican que la migración conduce a que las remesas tengan un efecto positivo en el crecimiento del patrimonio y por tanto en las transiciones de la pobreza estructural. Además señalan que estructuralmente los receptores de remesas pobres experimentan un crecimiento de su patrimonio mayor que los hogares no pobres, lo cual indica que las remesas permiten a los hogares pobres escapar estructuralmente de la pobreza.

\section{II.3. Estudios comparativos entre paises}

De los trabajos que marcan un referente para medir el impacto de las remesas en la pobreza de los países en desarrollo se encuentra el de Adams y Page (2005) quienes conjuntan datos de 71 países sobre pobreza, desigualdad, migración internacional y remesas. Estos autores buscan responder las siguientes preguntas: ¿Cuál es el efecto de la migración internacional en la pobreza en el mundo en desarrollo? ¿Cómo las remesas oficiales enviadas a casa por los migrantes internacionales afectan el nivel, el grado y la severidad de la pobreza en el mundo en desarrollo? Para contestar estas preguntas desarrollan un modelo econométrico con variables instrumentales. Los resultados a los que llegan proveen evidencia fuerte y robusta del impacto en la reducción de la pobreza, tanto de la migración internacional y de las remesas.

Acosta et al., (2008) realizan un estudio para 10 países de América Latina y el Caribe con el objetivo de conocer los efectos de las remesas en la pobreza y la desigualdad en varias dimensiones, utilizando datos agregados a nivel país y de encuestas a hogares representativas a nivel nacional. Los autores muestran que la migración y las remesas tienen efectos estadísticamente significativos en la reduc- 
ción de la pobreza, los cuales parecen operar mediante incrementos en el ingreso per cápita de los países receptores.

Entre los estudios recientes que indagan sobre la relación entre remesas y pobreza en distintos países en desarrollo se encuentra el trabajo de Hossain (2013), cuyo objetivo es medir el impacto de las remesas en los índices de recuento de la pobreza, en la brecha de la pobreza a $\$ 1.25$ dólares por día y en la brecha de la pobreza a \$2 dólares por día, utilizando un conjunto de datos panel para 44 países en desarrollo. Para probar si el impacto de participación de las remesas en el PIB es más fuerte en un determinado umbral, se realiza un análisis separado para 27 países que han registrado una participación de las remesas en el PIB de 2 por ciento o mayor. El autor plantea un sistema de ecuaciones simultáneas incorporando la variable remesas, y para tomar en cuenta el problema de endogeneidad, utiliza el método de mínimos cuadrados en tres etapas. Los resultados señalan que las remesas pueden reducir la pobreza en algunos países de la muestra; sin embargo, el proceso mediante el cual las remesas reducen la pobreza no pudo ser identificado.

En el trabajo de Azam, Haseeb y Samsudin (2016) se realiza un estudio empírico para determinar el impacto de las remesas internacionales junto con otras variables (ayuda externa, capital humano, inflación e ingreso) en el alivio de la pobreza en 39 países de ingresos bajos, medios altos y altos. Los resultados a los que llegan los autores, usando datos panel del periodo 1990-2014, revelan que tanto las remesas internacionales como la ayuda externa son factores notables del crecimiento económico, en el cual las remesas tienen un rol positivo, mientras que la ayuda externa tiene un rol negativo en la reducción de la pobreza. Este hallazgo significa que hay beneficios considerables relacionados con las remesas para las personas pobres. Por tanto, la importancia de los flujos de remesas no debe desestimarse en términos de la expansión del crecimiento y la mitigación de la pobreza, ya que mejoran exitosamente las condiciones económicas y sociales en los países de origen.

Hagen-Zanker y Leon (2016) elaboran un estudio que revisa la evidencia sobre el impacto comparativo de las remesas y las transferencias de efectivo en un amplio rango de indicadores de bienestar a nivel hogar en países con ingreso medio y bajo. Las autoras se preguntan si un dólar de transferencia en efectivo recibido por el hogar tiene el mismo impacto en la reducción de la pobreza que un dólar recibido por remesas. Afirman que hay un número de razones a priori para esperar que lo anterior no sea el caso. El artículo revisa todos los estudios que consideran la pregunta: ¿las remesas y las transferencias en efectivo tienen impactos diferentes en la pobreza y en la vulnerabilidad de los hogares? La respuesta a esta pregunta brinda información de cómo las transferencias monetarias son gastadas. En la mayoría de los estudios se demuestra que tanto las transferencias en efectivo y las remesas tienen impactos positivos en un rango de indicadores 
de bienestar. En general, las remesas parecen tener impactos más fuertes en la reducción de la pobreza; sin embargo, muchos de los estudios pueden tener una validez interna limitada.

\section{II.4. El caso de México}

Al igual que en el plano internacional, en el caso de México el estudio de los efectos que las remesas tienen en la pobreza de los individuos, hogares y comunidades receptoras cada vez ha recibido mayor atención por parte de la comunidad académica (Canales, 2016; García-Zárate, 2015; López-Córdova, 2005; Esquivel y Huerta-Pineda, 2007; Taylor et al., 2008).

En general, la evidencia encontrada señala que la recepción de remesas contribuye de manera positiva a erradicar la pobreza. Por ejemplo, Taylor et al., (2008) exploran el impacto de las remesas en la pobreza de los hogares rurales mexicanos. Sus resultados indican que un 10 por ciento de incremento en las remesas internacionales causan una reducción de 0.3 por ciento en la pobreza. Estos autores también analizan sus resultados a nivel regional y encuentran efectos diferenciados entre las regiones de México. Mientras que 10 por ciento de incremento de las remesas internacionales reducen la pobreza 1.64 por ciento en la región Centro-occidente, el mismo incremento reduce sólo 0.11 por ciento la pobreza en la región Sur-Sureste. Sus principales resultados señalan que las remesas internacionales reducen la pobreza rural en mayor medida que las remesas internas; cuánto más grande es la prevalencia de la migración en una región, más grande es el efecto de mejora en la pobreza rural. Utilizando la misma base de información, Lopez-Feldman (2011) encuentra que los efectos de las remesas en los índices de pobreza son mayores mientras la localidad analizada muestre mayores tasas de migración.

Empleando datos a nivel municipal, López-Córdova (2005) analiza el efecto de las remesas en distintos indicadores de desarrollo. Una de sus principales conclusiones es que las remesas tienen un efecto positivo pero débil en la pobreza y las condiciones de vida. En sintonía con estos resultados, un estudio reciente de Canales (2016) señala que a pesar de que las remesas sean una fuente importante en el ingreso de las familias, no son lo suficientemente relevantes para impulsar la movilidad social requerida que permita a las familias receptoras mejorar sus niveles de pobreza. A partir de ello, el autor sostiene que las remesas tienen un limitado impacto en la promoción del desarrollo y en la reducción de la pobreza, debido a que constituyen, en esencia, un fondo salarial. En este sentido, Orrenius y Zavodny (2005) indican que las tasas de empleo y salariales son mayores en los estados del país que tienen mayores índices de migración en comparación con aquellos con 
bajos niveles, lo cual implica que efectivamente se da una reducción en la pobreza, pero debido a un ingreso laboral mayor.

Dos investigaciones que emplean métodos cuasi-experimentales para analizar el efecto de las remesas en la pobreza son los trabajos de Esquivel y Huerta-Pineda (2007) y García-Zárate (2015). En el primer caso, los autores estudian el impacto de las remesas internacionales en la pobreza distinguiendo por áreas rurales y urbanas. Sus resultados indican que la recepción de remesas internacionales reduce la probabilidad de que los hogares se encuentren en pobreza en un monto mayor a seis puntos porcentuales. Estos efectos representan una reducción de alrededor de 30 por ciento en las tasas de pobreza correspondientes para un hogar receptor de remesas típico con respecto a un hogar no receptor. En el segundo trabajo, la autora pone especial atención en los efectos diferenciados de las remesas internas en contraste con las internacionales. Esta investigación enfatiza que, a diferencia de la mayoría de los estudios existentes, las remesas internas constituyen una fuente de ingreso de suma importancia y que representan mayor proporción en el ingreso total de los hogares, así mismo resulta mucho mayor el número de hogares que las reciben respecto a los que reciben remesas externas. No obstante dicha importancia relativa, los resultados señalan que las remesas internacionales disminuyen en mayor medida la pobreza en los hogares receptores.

Por su parte Chiodi, Jaimovich y Montes-Rojas (2012) utilizan una base de datos tipo panel de los beneficiarios del programa Oportunidades (antes Progresa y actualmente Prospera) para identificar que la migración y las remesas contribuyen a suavizar las restricciones productivas y de liquidez del sector rural mexicano. Dicha contribución origina efectos positivos en la acumulación de activos, lo cual contribuye a que las familias receptoras de remesas puedan salir de manera permanente de la pobreza. Empleando también información tipo panel que va de octubre de 1998 a noviembre de 2000, de la Fuente (2010) considera la relación entre pobreza y remesas desde una perspectiva dinámica que toma en cuenta el riesgo y los contextos de vulnerabilidad que podrían enfrentar los hogares y que potencialmente podrían influir en sus niveles de bienestar futuro. El autor emplea datos para cerca de dos mil hogares localizados en siete estados del territorio mexicano. Sus estimaciones encuentran una relación negativa y estadísticamente significativa entre el monto de remesas y el riesgo o amenaza a caer en pobreza en el futuro. El riesgo asociado, de no recepción de remesas, es mayor para los hogares más vulnerables de las localidades estudiadas, el cual podría atenuarse y ser menos problemático si en las comunidades rurales surgieran mayores acuerdos de solidaridad y reciprocidad, en dicho caso cualquier derrama de remesas internacionales podría permearse, incluso, hasta los hogares más necesitados. De esta manera las remesas 
podrían ser una herramienta que contribuya a la disminución de la pobreza de forma más sostenida.

En un estudio reciente de Campos y Sobarzo (2014) se presenta una revisión de algunos estudios que efectúan investigaciones empíricas de los efectos de la migración y las remesas sobre el desarrollo en México, diferenciando los impactos de la migración sobre el ingreso salarial y los efectos de las remesas sobre la pobreza y la acumulación de capital humano. Sus principales resultados señalan que las remesas representan el 2.5 por ciento del PIB en México y son una fuente muy importante de ingresos para algunos estados del país. Además, las remesas constituyen una fuente de ingresos importante para los hogares más pobres y ayudan a disminuir los niveles de pobreza. Adicionalmente, los autores recomiendan que sería muy deseable realizar mayores estudios que contribuyan a entender cómo los hogares receptores utilizan las remesas y con ello contribuir a desentrañar los efectos agregados de los impactos distributivos.

De manera adicional a las investigaciones sobre la relación entre las remesas y pobreza en México, Canales (2016) enfatiza que los programas del tipo 3x1, que buscan promover la inversión de los migrantes en proyectos productivos, aún tienen un impacto limitado en el logro de sus objetivos. Cabe señalar que el Programa 3x1 para Migrantes constituye un instrumento de política social del gobierno mexicano que transfiere recursos al nivel comunitario y articula la participación de los tres niveles de gobierno con las organizaciones civiles (Sedesol, 2017). Este programa pretende tener el potencial para impulsar el desarrollo de las comunidades de origen de los migrantes y promover la mejora en la calidad de vida de la población (Aparicio y Meseguer, 2012; Fernández de Castro, García y Vila, 2006). Para conseguir los resultados esperados, el programa coloca en el centro de su estrategia a un actor transnacional: los clubes de migrantes en Estados Unidos (Rodríguez, 2012). Desde sus inicios, el Programa 3x1 para Migrantes ha generado opiniones encontradas en relación con su efectividad para impulsar, a través de las remesas colectivas, el desarrollo en las localidades de origen, debido a los diferentes agentes sociales y gubernamentales que intervienen para su funcionamiento (García, 2007). Por un lado, existen aspectos positivos que tienen que ver con los logros que se han obtenido en las actividades realizadas durante los últimos años por los gobiernos federal, estatal y municipal, junto con los mexicanos residentes en los Estados Unidos (Rocha, 2008; Rodríguez, 2012). Por otro lado, se encuentra la existencia de aspectos negativos relacionados, precisamente, con el aprovechamiento de las remesas colectivas que envían los migrantes y con la eficiencia del programa para utilizar ese dinero a fin de impulsar el desarrollo en las localidades marginadas del país (Canales, 2005; García, 2007). 


\section{CONCLUSIONES}

Este trabajo presenta la revisión de estudios que exploran los impactos de las remesas en distintos indicadores de bienestar en los hogares de origen de los migrantes. Entre los indicadores más relevantes del bienestar se encuentra el nivel de pobreza de los habitantes en un espacio territorial determinado. La relación entre remesas y pobreza es el principal interés en este trabajo, tema que ha sido estudiado en forma regular desde las últimas décadas del siglo pasado. La evidencia empírica de los estudios analizados muestra que las remesas tienen, en general, efectos estadísticamente confiables en la reducción de la pobreza. Prácticamente existe consenso respecto a que las remesas ayudan a reducir el nivel de pobreza, sin embargo, existen aún cuestiones que están abiertas a la investigación que se relacionan con sus efectos a largo plazo en los hogares receptores de estos recursos (Amare y Hohfeld, 2016).

Las remesas constituyen una importante entrada de divisas a los países de origen, su magnitud se equipara a la inversión extranjera o a la ayuda internacional (Acosta et al., 2008). Además representan una parte considerable de las transferencias privadas en los países en desarrollo (Adams, 2006). Existen distintas motivaciones para remitir que han sido contrastadas empíricamente y los resultados más relevantes señalan que el envío de remesas es estable y se incrementa cuando los hogares en el país de origen tienen dificultades económicas (Yang, 2011).

Entre los estudios que se revisaron para evaluar el efecto de las remesas en la pobreza prevalecen aquellos que utilizan medidas de pobreza relacionadas con la parte monetaria, sin embargo, una opción que se está explorando es incorporar la medición desde la perspectiva multidimensional (García-Zárate, 2015; Hage-Zanker y Leon, 2016).

Los trabajos empíricos que estudian las remesas han encontrado dificultades metodológicas las cuales pueden provocar que en los resultados generados existan o contengan sesgos que no permitan captar correctamente el fenómeno en estudio (Adams, 2011). Para ello se han propuesto soluciones que permitan superar estas dificultades y entre ellas destacan el uso de datos panel y la introducción de variables instrumentales (Gibson, McKenzie y Zia, 2014; Yang, 2008). Estas propuestas constituyen una guía para futuras investigaciones junto con la mayor disponibilidad de datos a nivel estatal y nacional.

Realizar una revisión de los trabajos que abordan la relación entre remesas y pobreza implica una tarea de selección que puede ignorar estudios relevantes que ilustren o contengan aspectos no estudiados previamente y puedan abrir nuevas rutas para indagar la relación señalada. Nuestro trabajo se centró en explorar los trabajos que abrieron la discusión sobre los efectos de las remesas en los niveles 
de pobreza y procuró dar un seguimiento sobre el estado de dicha discusión en los aspectos teóricos y empíricos.

A partir de los estudios revisados fue posible establecer que en muchos países receptores de remesas, éstas constituyen una importante fuente de ingresos para los hogares más pobres. También se identificó que el impacto de las remesas depende en gran proporción de las estructuras institucionales existentes en los países de origen y de su efectividad al lidiar con problemas sociales y económicos. No obstante y aunque se identificó que las remesas ayudan en el combate a la pobreza, es imperante señalar que no pueden resolver el problema por sí solas y de ninguna manera deben ser vistas como un mecanismo destinado a erradicar los altos niveles de pobreza que padecen la mayoría de los países en desarrollo. Es decir, por sí mismas, las remesas no pueden eliminar restricciones estructurales y padecimientos sociales que aquejan a la mayoría de estos países. Así mismo, no resulta pertinente enfatizar sólo los beneficios que éstas conllevan, sino también los retos que originan.

Una de las consideraciones que nos deja la revisión efectuada es que en muy pocos países existen medidas de política que potencialicen el efecto de las remesas en los indicadores de desarrollo de las localidades de origen de los migrantes. Por tanto, es deseable que las autoridades mejoren los programas relacionados con el envío de remesas y diseñen medidas efectivas que incentiven y promuevan un mejor uso de estos flujos monetarios. Dados los beneficios que las remesas propician, definitivamente sería incorrecto subestimar su importancia no sólo en la economía mundial y en los ingresos nacionales, sino también en las posibilidades que les brindan a los hogares receptores del mundo entero.

\section{REFERENCIAS BIBLIOGRÁFICAS}

Abdih, Yasser; Chami, Ralph; Dagher, Jihad y Montiel, Peter (2012), "Remittances and Institutions: Are Remittances a Curse?", World Development, 40 (4), pp. 657-666.

Acosta, Pablo; Calderon, César; Fajnzylber, Pablo y Lopez, Humberto (2008), "What is the impact of international remittances on poverty and inequality in Latin America?”, World Development, 36 (1), pp. 89-114.

Adams, Richard (1991), "The Economic Uses and Impact of International Remittances in Rural Egypt", Economic Development and Cultural Change, University of Chicago Press, 39 (4), pp. 695-722.

(2004), "Economic Growth, Inequality and Poverty: Estimating the Growth Elasticity of Poverty", World Development, 32 (12), pp. 19892014. 
(2006), "International remittances and the household: Analysis and review of global evidence", Journal of African Economies, 15 (2), pp. 396425.

(2011), "Evaluating the Economic Impact of International Remittances On Developing Countries Using Household Surveys: A Literature Review", The Journal of Development Studies, 47 (6), pp. 809-828.

Adams, Richard y Cuecuecha, Alfredo (2013), "The Impact of Remittances on Investment and Poverty in Ghana", World Development, 50, pp. 24-40.

Adams, Richard y Page, John (2005), "Do International Migration and Remittances Reduce Poverty in Developing Countries?", World Development, 33 (10), pp. 1645-1669.

Alkire, Sabina y Foster, James (2007), "Recuento y medición multidimensional de la pobreza", OPHI Working Paper Series, Documento de trabajo OPHI, núm. 7.

Alkire, Sabina y Santos, María (2013), “A Multidimensional Approach: Poverty Measurement \& Beyond”, Social Indicators Research, 112 (2), pp. 239257.

Amare, Mulubrhan y Hohfeld, Lena (2016), "Poverty Transition in Rural Vietnam: The Role of Migration and Remittances", The Journal of Development Studies, 52 (10), pp. 1463-1478.

Ambrosius, Christian y Cuecueha, Alfredo (2016), "Remittances and the Use of Formal and Informal Financial Services", World Development, 77, pp. 80-98.

Amuedo-Dorantes, Catalina y Pozo, Susan (2006), "Remittances as insurance: evidence from Mexican immigrants", Journal of Population Economics, 19 (2), pp. 227-254.

(2004), "Workers' remittances and the real exchange rate: A paradox of gifts", World Development, 32 (8), pp. 1407-1417. (2011), "Remittances and income smoothing", American Economic Review, 101 (3) pp. 582-587.

Aparicio, Francisco y Meseguer, Covadonga (2012), "Collective Remittances and the State: The 3x1 Program in Mexican Municipalities", World Development, 40 (1), pp. 206-222.

Araujo, Caridad; Bosch, Mariano y Schady, Norbert (2016), “Can Cash Transfers Help Households Escape an Inter-Generational Poverty Trap?", (núm. w22670), National Bureau of Economic Research. 
Arezki, Rabah y Brückner, Markus (2012), "Rainfall, financial development, and remittances: Evidence from sub-Saharan Africa", Journal of International Economics, 82, pp. 377-385.

Atkinson, Anthony (1991), "Comparing Poverty Rates Internationally: Lessons from Recent Studies in Developed Countries", The World Bank Economic Review, 5 (1), pp. 3-21.

Azam, Muhammad; Haseeb, Muhammad y Samsudin, Shamzaeffa (2016), "The Impact of Foreign Remittances on Poverty Alleviation: Global Evidence", Economics and Sociology, 9 (1), pp. 264-281.

Azizi, SeyedSoroosh (2017), "Altruism: Primary Motivation of Remittances", Applied Economic Letters, 24 (9).

Batista, Catia y Umblijs, Janis (2016), "Do migrants send remittances as a way of self-insurance?”, Oxford Economic Papers, 68 (1), pp. 108-130.

Battiston, Diego; Cruces, Guillermo; Lopez-Calva, Luis; Lugo, María y Santos, María (2013), "Income and Beyond: Multidimensional Poverty in Six Latin American Countries", Social Indicators Research, 112 (2), pp. 291-314.

Bourguignon, Francois y Chakravarty, Satya (2003), "The measurement of multidimensional poverty", Journal of Economic Inequality, 1, pp. 25-49.

Brown, Stuart (2006), "Can Remittances Spur Development? A Critical Survey", International Studies Review, 8 (1), pp. 55-75.

Campos-Vazquez, Raymundo y Sobarzo, Horacio (2014), "The effects of emigration on development and fiscal outcomes in Mexico", International Journal of Migration and Border Studies, 1 (2), pp. 190-216.

Canales, Alejandro (2005), "El papel de las remesas en la configuración de las relaciones familiares trasnacionales", Papeles de Población, 11 (44), pp. 149-172.

(2016), "El papel de las remesas en la reducción de la pobreza en México. Mitos y realidades", Carta Económica Regional, (98).

Catrinescu, Natalia; Leon-Ledezma, Miguel; Piracha, Matloob y Quillin. Bryce (2009), "Remittances, Institutions, and Economic Growth", World Development, 37 (1), pp. 81-92.

Chakraborty, Tanika; Mirkasimov, Bakhrom y Steiner, Susan (2015), "Transfer behavior in migrant sending communities", Journal of Comparative Economics, 43, pp. 690-705.

Chami, Ralph; Fullenkamp, Connel y Jahjah, Samir (2005), “Are immigrant remittance flows a source of capital for development?", IMF Staff Papers, 52 (1), pp. 55-81. 
Chami, Ralph; Cosimano, Thomas y Gapen, Michael (2006), "Beware of emigrants bearing gifts: optimal fiscal and monetary policy in the presence of remittances", IMF Working Paper WP/06/61.

Chiodi, Vera; Jaimovich, Eesteban y Montes-Rojas, Gabriel (2012), "Migration, Remittances and Capital Accumulation: Evidence from Rural Mexico", Journal of Development Studies, 48 (8), pp. 1139-1155.

Consejo Nacional de Evaluación de la Política de Desarrollo Social (Coneval) (2015), "Medición de la Pobreza en México y en las Entidades Federativas 2014", Coneval. Recuperado de www.coneval.gob.mx el 10 de noviembre de 2015.

Consejo Nacional de Población, Fundación BBVA Bancomer y BBVA Research (2015), Anuario de Migración y Remesas, México 2016, México, Conapo-Fundación BBVA Bancomer-BBVA Research.

Cox, Alejandra y Ureta, Manuelita (2003), "International Migration, Remittances, and Schooling: Evidence from El Salvador", Journal of Development Economics, 72 (2), pp. 429-461.

Cox, Donald (1987), "Motives for Private Income Transfers", Journal of Political Economy, 95 (3), pp. 508-546.

Cox, Donald; Eser, Zekeriya y Jimenez, Emmanuel (1998), "Motives for private transfers over the life cycle: An analytical framework and evidence for Peru", Journal of Development Economics, 55 (1), pp. 57-80.

De Haas, Hein (2010), "Migration and Development: A Theoretical Perspective", International Migration Review, 44 (1), pp. 227-264.

Denis, Angela; Gallegos, Francisca y Sanhueza, Claudia (2010), Medición de pobreza multidimensional en Chile, Chile, Universidad Alberto Hurtado. Department for International Development (DFID) (2011), Cash Transfers Literature Review, London, Department for International Development.

Docquier, Frederic y Rapoport, Hillel (1998), “Are Migrant Minorities Strategically Self-Selected?", Journal of Population Economics, 11 (4), pp. 579588.

Docquier, Frederic; Rapoport, Hillel y Salomone, Sara (2012), "Remittances, migrants' education and immigration policy: Theory and evidence from bilateral data", Regional Science and Urban Economics, 42, pp. 817828.

Doi, Yoko; McKenzie, David y Zia, Bilal (2014), "Who you train matters: Identifying combined effects of financial education on migrant households", Journal of Development Economics, 109, pp. 39-55. 
Domínguez, Juana y Martín, Ana (2006), "Medición de la pobreza: una revisión de los principales indicadores", Revista de Métodos Cuantitativos para la Economía y la Empresa, (2), pp. 27-66.

Durand, Jorge; Kandel, William; Parrado, Emilio y Massey, Douglas (1996), "International migration and development in Mexican communities", Demography, 33 (2), pp. 249-264.

Esquivel, Gerardo y Huerta-Pineda, Alejandra (2007), "Las remesas y la pobreza en México: un enfoque de pareo de puntuación de la propensión”, Integración y Comercio, (27), pp. 47-74.

Feres, Juan y Mancero, Xavier (2001), "Enfoques para la medición de la pobreza", CEPAL. Serie de estudios estadísticos y prospectivos, núm. 4, CEPAL.

Fernández de Castro, Rafael; García Zamora, Rodolfo y Vila, Ana (coords.) (2006), El Programa $3 X 1$ para migrantes. ¿Primera política transnacional en México?, México, Miguel Ángel Porrúa-UAZ-ITAM.

Fondo Monetario Internacional (FMI) (2009), Manual de Balanza de Pagos y Posición de Inversión Internacional, Washington, D. C., International Monetary Fund.

Foster, James; Greer, Joel y Thorbecke, Erik (1984), "A Class of Decomposable Poverty Measures”, Econometrica, 52 (3), pp. 761-766.

Fuente, Alejandro de la (2010), "Remittances and vulnerability to poverty in rural Mexico", World Development, 38 (6), pp. 828-839.

García Zamora, Rodolfo (2007), "El Programa Tres por Uno de remesas colectivas en México: Lecciones y desafíos", Migraciones Internacionales, 4 (1), pp. 165-172.

García-Zárate, Teresa (2015), "Impacto de las remesas internas y externas en la reducción de la pobreza en México: Un análisis a nivel de viviendas a partir de técnicas de Propensity Score Matching (PSM)", Papeles de Población, 21 (86), pp. 105-145.

Gibson, John; McKenzie, David y Stillman, Steven (2013), “Accounting for Selectivity and Duration-Dependent Heterogeneity When Estimating the Impact of Emigration on Incomes and Poverty in Sending Areas", Economic Development and Cultural Change, 61 (2), pp. 247-280.

Gibson, John; McKenzie, David y Zia, Bilal (2014), “The impact of financial literacy training for migrants", World Bank Economic Review, 28 (1), pp. 130-161.

Giuliano, Paola y Ruiz-Arranz, Marta (2009), "Remittances, financial development, and growth", Journal of Development Economics, 90 (1), pp. 144-152. 
Gómez, Pablo (2013), "Migraciones, remesas internacionales y desarrollo en el cono sur de América Latina: perspectivas analíticas", Estudios, 30, pp. 159-175.

Guha, Puja (2013), "Macroeconomic effects of international remittances: The case of developing economies", Economic Modelling, 33, pp. 292-305.

Hagen-Zanker, Jessica y Leon, Carmen (2016), "How Effective Are Cash Transfers in Reducing Poverty, Compared to Remittances?", Social Policy \& Society, 15 (1), pp. 29-42.

Hagen-Zanker, Jessica y Siegel, Melissa (2007), "The determinants of remittances: A review of literature", Working Paper MGSoG/2007/WP003, Maastricht Graduate School of Governance.

Hatemi-J, Abdulnasser y Salah, Gazi (2014), "On the causal nexus of remittances and poverty reduction in Bangladesh", Applied Economics, 46 (4), pp. 374-382.

Hobbs, Andrew y Jameson, Kenneth (2012), "Measuring the effect of bi-directional migration remittances on poverty and inequality in Nicaragua", Applied Economics, 44 (19), pp. 2451-2460.

Hoddinott, John (1994), "A model of migration and remittances applied to Western Kenya”, Oxford Economic Papers, 46 (30), pp. 459-476.

Hossain, Mohammad (2013), "An empirical investigation of the impact of foreign remittances on poverty in developing countries", 9th Asian Business Research Conference, Bangladesh.

Ilahi, Nadeem y Jafarey, Saqib (1999), "Guestworker migration, remittances and the extended family: Evidence from Pakistan", Journal of Development Economics, 58, pp. 485-512.

Joseph, George y Wodon, Quentin (2014), "Does the Impact of Remittances on Poverty and Human Development Depend on the Climate of Receiving Areas?", MPRA Paper, núm. 56517.

Levitt, Peggy y Lamba-Nieves, Deepak (2011), "Social Remittances Revisited”, Journal of Ethnic \& Migration Studies, 37 (1), pp. 1-22.

Levy, Santiago (2006), Progress against Poverty. Sustaining Mexico's Progresa-Oportunidades Program, Washington D. C., Brookings Institution Press.

López Calva, Luis y Ortiz, Eduardo (2009), "Medición multidimensional de la pobreza en México: significancia estadística en la inclusión de dimensiones no monetarias", Estudios Económicos, núm. extraordinario, pp. 3-33. 
López-Córdova, Ernesto (2005), "Globalization, migration, and development: the role of Mexican migrant remittances", Economía, 6 (1), pp. 217-256.

Lopez-Feldman, Alejandro (2011), "Migration history, remittances and poverty in rural Mexico", Economics Bulletin, 31 (2), pp. 1256-1264.

Lucas, Robert y Stark, Oded (1985), "Motivations to remit: evidence from Botswana", Journal of Political Economy, 93, pp. 901-918.

Majeed, Muhammad (2015), "Poverty effects of remittances: a comparative analysis", Journal of International Development, 27, pp. 1-14.

Manic, Marian (2016), "The impact of remittances on regional consumption and investment", Journal of Regional Science, pp. 1-40.

McKenzie, David (2005), "Beyond Remittances: The Effects of Migration on Mexican Households", en Ozden, C. y Schiff, M. (eds.), International Migration, Remittances and the Brain Drain, Washington D.C., The World Bank.

McKenzie, David; Gibson, John y Stillman, Steven (2007), "Moving to opportunity, leaving behind what? Evaluating the initial effects of a migration policy on incomes and poverty in source areas", New Zealand Economic Papers, 41 (2), pp. 197-224.

Monni, Salvatore y Pallottino, Massimo (2016), “A New Agenda for International Development Cooperation: Lessons learnt from the Buen Vivir experience", Development, 58 (1), pp. 49-57.

oeCD (2013), Development Co-operation Report 2013: Ending Poverty, oeCD Publishing.

Organización de las Naciones Unidas (2015), Carta de las Naciones Unidas. Recuperado de http://www.un.org/es/documents/charter/chapter1.shtml

Orozco, Manuel (2004), The remittance marketplace: Prices, policy and financial institutions, Washington, D. C., Pew Hispanic Center.

Orrenius, Pia y Zavodny, Madeline (2005), "Self-selection among undocumented immigrants from Mexico", Journal of Development Economics, 78 (1), pp. 215-240.

Osaki, Keiko (2003), "Migrant remittances in Thailand: Economic necessity or social norm", Journal of Population Research, 20 (2), pp. 203-222.

Osili, Una Okonkwo (2004), "Migrants and housing investments: Theory and evidence from Nigeria", Economic Development and Cultural Change, 52 (4), pp. 821-849.

(2007), "Remittances and savings from international migration: Theory and evidence using a matched sample", Journal of Development Economics, 83, pp. 446-465. 
Ponce, María (2013), "Pobreza y bienestar: una mirada desde el desarrollo", Cuadernos del Cendes, 83 (1), pp. 1-21.

Programa de las Naciones Unidas para el Desarrollo (PNUD) (1997), Informe sobre desarrollo humano 1997. Desarrollo humano para erradicar la pobreza, Madrid, Ediciones Mundi-Prensa.

(2014), Informe sobre desarrollo humano 2014. Sostener el progreso humano: reducir vulnerabilidades y construir resiliencia. Resumen, Nueva York, PNUD. Recuperado de http:/hdr.undp.org/sites/default/files/ hdr14-summary-es.pdf.

(2016), Una nueva agenda de desarrollo sostenible. Recuperado de http://www.undp.org/content/undp/es/home/sdgoverview.html

Quang, Pham (2015), Multidimensional Poverty and Migrant Households- a Case Study of Vietnam, Master dissertation, Department of Economics, Macquarie University.

Rapoport, Hillel y Docquier, Frederic (2006), “The Economics of Migrants' Remittances", Handbook of the Economics of Giving, Altruism and Reciprocity, vol. 2, pp. 1135-1198.

Ratha, Dilip y Mohapatra, Sanket (2007), "Increasing the Macroeconomic Impact of Remittances on Development", Paper presented at G8 Outreach Event on Remittances, World Bank, Berlin.

Rocha, Alina (2008), Programa 3xl para Migrantes, Documento de trabajo del Social Cohesion Practical Experiences and Iniciatives. Consultado el 4 de febrero de 2017. Recuperado de https://www.odi.org/sites/odi.org.uk/ files/odi-assets/publications-opinion-files/1914.pdf

Rodríguez, Héctor (2012), "El papel de los migrantes mexicanos en la construcción de una agenda de políticas públicas. El caso del Programa 3x1", Región y Sociedad, 24 (53), pp. 231-257.

Rowntree, B. Seebohm (1901), Poverty. A Study of Town Life, London, McMillan.

Sánchez Almanza, Adolfo (2010), "La pobreza y conceptos afines”, en Villarespe, V. (coord.), Pobreza: concepciones, mediciones y programas. México, UNAM-IIEC.

Sánchez, Víctor (2010), "Remesas y pobreza multidimensional en México: el caso de la población rural", (tesis de maestría), El Colegio de la Frontera Norte.

Satti, Saqlain; Hassan, Muhammad; Hayat, Fozia y Paramati, Sudharshan (2016), "Economic Growth and Inflow of Remittances: Do They Combat Poverty 
in an Emerging Economy?", Social Indicators Research, 127 (3), pp. 1119-1134.

Sedesol (2017), Reglas de Operación del Programa 3X1 para Migrantes.

Sen, Amartya (1976), "Poverty: An Ordinal Approach to Measurement", Econometrica, 44 (2), pp. 219-231.

(1983), "Poor, Relatively Speaking”, Oxford Economic Papers, New Series, 35 (2, pp. 153-169.

Sierra, Iván (2015), International Development Cooperation: A Practitioner's Roadmap, Guadalajara, Groppe Libros.

Sindi, Kirimi y S. Kimiri, Lilian (2006), "A Test of the New Economics of Labor Migration Hypothesis: Evidence from Rural Kenya”, Selected Paper prepared for presentation at the American Agricultural Economics Association Annual Meeting, Long Beach, CA.

Spicker, Paul (2007), "Definitions of poverty: twelve clusters of meaning", Poverty: An international glossary, pp. 229-243. Recuperado de http://dds. cepal.org/.

Stark, Oded (1991), The migration of labor, Cambridge, MA, Blackwell. (1995), Altruism and Beyond, Oxford and Cambridge, Basil Blackwell.

Stark, Oded y Bloom, David (1985), "The New Economics of Labor Migration", The American Economic Review, 75 (2), pp. 173-178.

Stephenson, Andrew V. y Wilsker, Amanda (2016), "Efectos de consumo de las remesas extranjeras en Jamaica", International Advances in Economic Research, vol. 22, núm. 3, pp. 309-320.

Taylor, Edward; Rozelle, Scott y de Brauw, Alan (2003), "Migration and Incomes in Source Communities: A New Economics of Migration Perspective from China", Economic Development and Cultural Change, 52, pp. 75-101.

Taylor, Edward; Mora, Jorge; Adams, Richard y Lopez-Feldman, Alejandro (2008), "Remittances, Inequality and Poverty: Evidence from Rural Mexico", en De Wind, J. y Holdaway, J. (eds.), Migration and Development Within and Across Borders: Research and Policy Perspectives on Internal and International Migration, Ed. IOM and SSRC.

Tchouassi, Gerard (2010), "Altruistic preferences as motivation for migrants in the diaspora to remit to home communities", Research in Applied Economics, 2, pp. 1-18.

Townsend, Peter (1993), "La conceptualización de la pobreza", Comercio Exterior, 53 (5), pp. 445-452. 
Wagle, Udaya (2012), "Socioeconomic Implications of the Increasing Foreign Remittance to Nepal: Evidence from the Nepal Living Standard Survey", International Migration, 50 (4), pp. 186-207.

World Bank (2013), Migration and Development Brief, Washington, D. C., Migration and Remittances Unit, Development Prospects Group, World Bank. (2015), "Pobreza: Panorama general", Recuperado de http://www.bancomundial.org/es/topic/poverty/overview

Yang, Dean (2008), "International migration, remittances, and household investment: Evidence from Philippine migrants' exchange rate shocks", Economic Journal, 118, pp. 591-630.

(2011), "Migrant Remittances", Journal of Economic Perspectives, 25 (3), pp. 129-152.

Yang, Dean y Martinez, Claudia (2006), "Remittances and poverty in migrants' home areas: evidence from the Philippines", en Ozden, C. y Schiff, M. (eds.), International Migration, Remittances and the Brain Drain, Washington, D. C., World Bank, pp. 82-122. 
